\title{
Hoe 140 a new potent and long acting bradykinin-antagonist: in vivo studies
}

\author{
${ }^{1}$ K. Wirth, F.J. Hock, U. Albus, W. Linz, H.G. Alpermann, H. Anagnostopoulos, St. Henke, \\ G. Breipohl, W. König, J. Knolle \& B.A. Schölkens
}

Hoechst AG, Pharmaceutical Division, PGU Heart Circulation, P.O. Box 8003 20, D-6230, Frankfurt/M. 80, F.R.G.

1 The potency, duration of action and tolerability of Hoe 140, a novel and highly potent bradykinin (BK) antagonist in vitro, has been tested in different in vivo models and compared with the well-known BK antagonist D-Arg-[Hyp $\left.{ }^{2}, \mathrm{Thi}^{5,8}, \mathrm{D}-\mathrm{Phe}^{7}\right] \mathrm{BK}$.

2 Hoe 140 is highly potent and long acting in inhibiting BK-induced hypotensive responses in the rat. Four hours after s.c. administration of $20 \mathrm{nmol} \mathrm{kg}^{-1}$, inhibition still amounted to $60 \%$ whereas the effect of $200 \mathrm{nmol} \mathrm{kg}^{-1}$ of D-Arg-[Hyp ${ }^{2}$, Thi $\left.^{5,8}, \mathrm{D}-\mathrm{Phe}^{7}\right] \mathrm{BK}$ was not significant.

3 BK-induced bronchoconstriction in guinea-pigs was strongly inhibited by Hoe 140. The magnitude and duration of inhibition confirmed the findings obtained in the blood pressure experiments in the rat.

4 Carrageenin-induced inflammatory oedema of the rat paw was considerably inhibited at i.v. doses between 0.1 and $1 \mathrm{mg} \mathrm{kg}^{-1}$.

5 In conscious dogs, intravenous doses of 0.01 and $0.1 \mathrm{mg} \mathrm{kg}^{-1}$ of $\mathrm{Hoe} 140$ and D-Arg-[Hyp ${ }^{2}, \mathrm{Thi}^{5,8}$, D-Phe $\left.{ }^{7}\right]$ BK were well tolerated. At doses of $1 \mathrm{mg} \mathrm{kg}^{-1}$ adverse effects occurred that were attributed to the residual BK agonistic activity of both compounds.

6 Hoe 140 has been shown to be a highly potent and long acting BK antagonist in vivo in different animal species and models. This makes it appropriate to investigate further the physiological and pathophysiological role of BK.

\section{Introduction}

Hoe 140 is a highly potent, novel and original $\mathrm{BK}_{2}$-receptor antagonist of bradykinin (BK) as shown in vitro in receptor binding assay, in isolated smooth muscle preparations, endothelium-derived relaxing factor (EDRF)-release and prostacyclin (PGI ${ }_{2}$-release (Hock et al., 1991). It exceeds the potency of the hitherto known antagonists by at least two orders of magnitude.

The aim of the present study was to test the efficacy of Hoe 140 in vivo in models where BK served as an agonist. For this purpose, models of BK-induced hypotensive reaction and BKinduced bronchoconstriction were used to demonstrate its high potency and long duration of action. For comparison, the BK antagonist D-Arg-[ $\left.\mathrm{Hyp}^{2}, \mathrm{Thi}^{5,8}, \mathrm{D}-\mathrm{Phe}^{7}\right] \mathrm{BK}$ which is representative of the class of antagonists synthesized by Stewart (Vavrek \& Stewart 1985) was used in blood pressure experiments. To show the efficacy and therapeutic potential of Hoe 140 in a standard model of inflammation the carrageenin-induced rat paw oedema model was selected which has been shown to be highly predictive of antiinflammatory drug activity in human inflammatory disease. Furthermore, tolerability of Hoe 140 was tested in dogs.

\section{Methods}

Duration of action of Hoe 140 assessed by inhibition of bradykinin-induced hypotensive responses in anaesthetized rats

Intra-arterial infusion of bradykinin-antagonists The method of Griesbacher et al. (1989) was used; 26 male Sprague Dawley rats (Moellegard, Skensved, DK) weighing between 320 and $350 \mathrm{~g}$ were anaesthetized with sodium thiopentone (Trapanal, $100 \mathrm{mg} \mathrm{kg}^{-1}$, i.p.). Systemic blood pressure was measured directly in the left femoral artery by use of a Statham pressure transducer $(\mathrm{P} 23 \mathrm{Db})$, connected to an 8channel recorder (Hellige GmbH, Freiburg, F.R.G.).

\footnotetext{
${ }^{1}$ Author for correspondence.
}

BK was dissolved in saline with $0.1 \%$ bovine serum albumin (BSA) and given as a bolus injection $(100 \mathrm{pmol}$ in $0.1 \mathrm{ml}$ i.a.) into the aorta via a cannula in the left carotid artery.

Hoe 140 and D-Arg- $\left[\mathrm{Hyp}^{2}, \mathrm{Thi}^{5,8}, \mathrm{D}-\mathrm{Phe}^{7}\right] \mathrm{BK}$ were freshly dissolved with $0.1 \% \quad$ BSA and doses of 0.015 and $0.15 \mathrm{nmol} \mathrm{min}-1$ were inflused i.a. at an infusion rate of $0.15 \mathrm{ml} \mathrm{min}^{-1}$ with a Braun-Melsungen perfusor (Unita II). The infusion was started $4 \mathrm{~min}$ before the third injection of BK and lasted for $5 \mathrm{~min}$. In control animals the vehicle was given instead of the antagonist.

Subcutaneous administration of bradykinin-antagonist In a further experiment in rats, doses of $20 \mathrm{nmol} \mathrm{kg}^{-1}$ Hoe 140 $\left(0.1 \mathrm{ml} \mathrm{kg}^{-1}\right)$ and $200 \mathrm{nmol} \mathrm{kg}^{-1} \mathrm{D}-\mathrm{Arg}-\left[\mathrm{Hyp}^{2}, \mathrm{Thi}^{5,8}, \mathrm{D}-\mathrm{Phe}^{7}\right]$ BK were given subcutaneously. BK was injected before and at regular intervals after administration of both compounds.

Effect of Hoe 140 on bradykinin-induced bronchoconstriction in the anaesthetized guinea-pig

Guinea-pigs (Hoechst breeding farm) of either sex weighing $400-600 \mathrm{~g}$ were anaesthetized with $70 \mathrm{mg} \mathrm{kg}^{-1}$ pentobarbitone i.p. and prepared for catherization of the trachea, oesophagus, jugular vein and carotid artery. Pulmonary function was assessed according to the method described by Chapman et al. (1985) with some modifications. The animals were mechanically ventilated with a Starling respiratory pump at a rate of 60 strokes $\min ^{-1}$. Inspiratory volume was determined by maintaining the inspiratory tracheal pressure at a constant level of $8 \mathrm{~cm}$ water.

Succinylcholine chloride $\left(1 \mathrm{mg} \mathrm{kg}^{-1}\right.$, i.v.) was injected for deep muscle relaxation in order to prevent interference from spontaneous respiration. The animals were placed inside a whole body plethysmograph and the tracheal, oesophageal, venous and arterial catheters were connected to onset ports in the wall of the plethysmograph. The tracheal port was connected to a respirator pump and airflow $(\dot{V})$ rates into and out of the plethysmograph were measured as a pressure difference with a Fleisch tube No. 000 and a differential pressure transducer (PM 97 TC, Hellige GmbH, Freiburg, F.R.G.). $\dot{V}$ was calibrated by passing compressed air through a rotameter. 
The tidal volume (VT) was calculated from the flow signal by computer. A calibrated differental pressure transducer (PM 97 TC, Hellige GmbH, Freiburg, F.R.G.) was used to measure the pressure difference between the tracheal port and the oesophagus-catheter representing the transpulmonary pressure (PTP). Calibration of PTP was with a water manometer. The airflow, tidal volume, and transpulmonary pressure signals were fed into an on-line computer system (PO-NEMAH, Model PF-1, Storrs) for calculation of pulmonary resistance $\left(R_{L}\right)$ and dynamic lung compliance $\left(C_{D y n}\right)$. Computation of these parameters was performed for each breath with a sampling rate of $100 \mathrm{~Hz}$ for each cycle. Flow and pressure signals for computation were obtained from PLUGSYSmeasuring system (Hugo Sachs Elektronik, Freiburg, F.R.G.) Systemic arterial blood pressure was measured with a Statham pressure transducer $($ P23 Db) and heart rate was obtained from pressure pulses.

In preliminary experiments the i.v. dose of BK that increased $\mathbf{R}_{\mathbf{L}}$ by about $50 \%$ was selected. However, tachyphylaxis occurred after repeated injections. Propranolol $\left(10 \mathrm{mg} \mathrm{kg}^{-1}\right.$, s.c.) was needed in order to obtain consistent BK responses throughout the whole experimental period (Lau et al., 1989) and allowed a reduction of the dose of BK by a factor of ten, which did not lower blood pressure. The doses of BK (between 300 and 600 pmol i.v.) were individually adapted to the animals and the selected dose injected at intervals of $10 \mathrm{~min}$ for the i.v. and $30 \mathrm{~min}$ for the s.c. dose of Hoe 140 throughout the experiment. In preliminary experiments $(n=6)$ it was established that BK injections at intervals of $10 \mathrm{~min}$ induced reproducible changes in $R_{L}$ and $C_{D y n}$ for at least $1 \mathrm{~h}$. In a small number of animals tachyphylaxis was observed during the initial control injections. In these animals, each subsequent dose of BK was increased by up to $100 \%$ of the previous dose in order to maintain a consistent rise in $R_{L}$.

\section{Carrageenin-induced paw oedema in rats}

The method described by Winter et al. (1962) was employed. Groups of 5 male rats (Sprague-Dawley, Möllegard, Skensved DK, about $120 \mathrm{~g}$ ) deprived of food overnight were treated intravenously with the test compound, immediately before carrageenin was injected into the left hind paw. Paw volume was measured by water displacement before and 1,2 and $3 \mathrm{~h}$ after injection of carrageenin. Hoe 140 was dissolved in physiological saline and administered into the tail vein at a volume of $1 \mathrm{ml} \mathrm{kg}^{-1}$. Carrageenin was made up $0.5 \%$ in saline. Each rat received $0.1 \mathrm{ml}$ of the irritant.

\section{Effects of i.v. administration on blood pressure and heart rate in conscious dogs}

The experiments were carried out in 4 male and 1 female Beagle dogs (Hoechst breeding farm), weighing between 13.5 and $19 \mathrm{~kg}$. An ultrasonic blood pressure monitor (Roche Arteriosonde 1011) was positioned on the dog's tail for indirect measurement of blood pressure and heart rate.

D-Arg- $\left[\mathrm{Hyp}^{2}, \mathrm{Thi}^{5,8}, \mathrm{D}-\mathrm{Phe}^{7}\right] \mathrm{BK}$ and Hoe 140 were given intravenously over $1 \mathrm{~min}$ to the conscious dogs in increasing doses of $0.01,0.1$, and $1 \mathrm{mg} \mathrm{kg}^{-1}$. Blood pressure measurements were done before and 1, 3, 5, 10 and $15 \mathrm{~min}$ after application of the substances or vehicle (saline $0.2 \mathrm{ml} \mathrm{kg}^{-1}$, i.v.) After a period of about $1.5 \mathrm{~h}$ the next dose was administered.

\section{Drugs}

Hoe 140 and D-Arg-[Hyp ${ }^{2}$, Thi ${ }^{5,8}$, D-Phe $\left.{ }^{7}\right]$ BK (Vavrek \& Stewart, 1985) were synthesized in Pharma Sythesis at Hoechst AG and were freshly dissolved for each experiment in physiological saline. BK was taken from a frozen stock solution and diluted in physiological saline. All other compounds were purchased from commercial sources.

\section{Statistics}

Paired and unpaired data were analyzed for statistical significance $(P<0.05)$ with the appropriate Student's $t$ test (Sachs, 1984).

\section{Results}

Duration of action of Hoe 140 assessed by inhibition of bradykinin-induced hypotensive responses in anaesthetized rats

Intra-arterial infusion of bradykinin-antagonists Intra-arterial injections of $100 \mathrm{pmol}$ BK transiently decreased the mean arterial blood pressure (MAP) of 121 to $130 \mathrm{mmHg}$ by 29 to $39 \mathrm{mmHg}$ (range of the means of the groups). In control animals repeated injections of BK at intervals of $10 \mathrm{~min}$ consistently produced a transient drop in blood pressure. No tachyphylaxis occurred.

When D-Arg-[Hyp $\left.{ }^{2}, \mathrm{Thi}^{5,8}, \mathrm{D}-\mathrm{Phe}{ }^{7}\right] \mathrm{BK}(0.75 \mathrm{nmol})$ was infused i.a. over $5 \mathrm{~min}$ it attenuated the BK-induced drop in MAP by $56 \%$ when compared with the values before antagonist infusion. A reduction by $30 \%$ was still observed $20 \mathrm{~min}$ after the start of the infusion. From this time course, a half life of the effect of 10 to $15 \mathrm{~min}$ was estimated. Hoe 140 $(0.075 \mathrm{nmol})$ infused i.a. over $5 \mathrm{~min}$ attenuated the BK-induced drop in MAP by $58 \%$. This effect was about equipotent to the effect obtained with the infusion of $0.75 \mathrm{nmol} \mathrm{D}$-Arg-[Hyp ${ }^{2}$, $\mathrm{Thi}^{5,8}$, D-Phe $\left.{ }^{7}\right] \mathrm{BK}$ for the first injection of BK after starting infusion of the BK-antagonists. A half life for the effect of about 30 min was estimated for this dose of Hoe 140.

At an equimolar dose of $0.75 \mathrm{nmol}$, infused over $5 \mathrm{~min}$, Hoe 140 completely prevented the BK-induced fall in blood pressure. Sensitivity to BK returned after $10 \mathrm{~min}$, but even $1 \mathrm{~h}$ after the start of the infusion the response to BK was still impaired by $71 \%$. It is concluded that at this dose, the half life is longer than $60 \mathrm{~min}$.

Subcutaneous administration of bradykinin-antagonists Injections of BK decreased MAP of 115 to $122 \mathrm{mmHg}$ by 27 to $30 \mathrm{mmHg}$ (range of the means of the groups). BK-antagonism by s.c. injections of $20 \mathrm{nmol} \mathrm{kg}^{-1}$ of Hoe 140 lasted for more than $5 \mathrm{~h}$. One hour after subcutaneous administration the inhibition was still complete, whereas at $5 \mathrm{~h}$ the BK-induced fall in MAP was $12 \mathrm{mmHg}$. Thus, the response to BK was impaired by $60 \%$. This means that the biological half life is longer than $5 \mathrm{~h}$ for Hoe 140 (Figure 1). In contrast, the effects of D-Arg- $\left[\mathrm{Hyp}^{2}, \mathrm{Thi}^{5.8}, \mathrm{D}-\mathrm{Phe}^{7}\right] \mathrm{BK}$ were not significant although given at a ten times higher dose than Hoe 140.

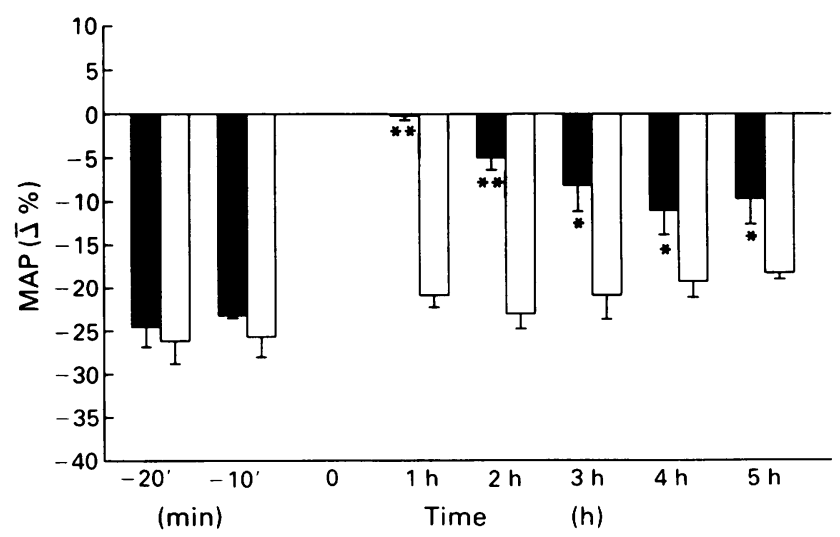

Figure 1 Inhibition of bradykinin (BK)-induced hypotensive responses in rats by $20 \mathrm{nmol} \mathrm{kg}^{-1}$ Hoe 140 (solid columns) injected subcutaneously (time zero) in comparison to the vehicle (open columns). BK (100 pmol) was given i.a. Each column represents the mean of \% change in mean arterial pressure (MAP) of 6 animals with s.e.mean shown by vertical bars. ${ }^{* *} P<0.001$ and $* P<0.05$ compared with the vehicle. 
Effect of Hoe 140 on bradykinin-induced bronchoconstriction in the anaesthetized guinea-pig

BK in doses of 300 to 600 pmol i.v. per animal increased $R_{L}$ by $42-58 \%$ compared to baseline levels $\left(0.28 \pm 0.01 \mathrm{cmH}_{2} \mathrm{O}\right.$ $\mathrm{ml}^{-1} \mathrm{~s}^{-1}$ ), while $\mathrm{C}_{\text {Dyn }}$ decreased by 33 to $39 \%$ $\left(0.34 \pm 0.03 \mathrm{ml} \mathrm{cm}^{-1}\right.$ water). Hoe 140,1 to $1000 \mathrm{pmol} \mathrm{kg}^{-1}$ i.v., caused a dose-dependent inhibition of BK-induced bronchoconstriction with ID 50 values of $13.4 \mathrm{pmol} \mathrm{kg}^{-1}$ for $R_{L}$ and $31.8 \mathrm{pmol} \mathrm{kg}^{-1}$ for $\mathrm{C}_{\mathrm{Dyn}}$ (Figure 2).

Maximum effects were seen $1 \mathrm{~min}$ after administration of Hoe 140. The response to BK was completely re-established within $5 \mathrm{~min}$ following $1 \mathrm{pmol} \mathrm{kg}^{-1}$, within $10 \mathrm{~min}$ after $10 \mathrm{pmol} \mathrm{kg}^{-1}$ and within $10-20 \mathrm{~min}$ after $100 \mathrm{pmol} \mathrm{kg}^{-1}$ of Hoe 140. Following administration of $1 \mathrm{nmol} \mathrm{kg}^{-1}$ however, BK-induced increase in $R_{L}$ was still inhibited by $60 \%$ after $1 \mathrm{~h}$ (Figure 3) and the decrease in $C_{D y n}$ by $46 \%$. BK-induced bronchoconstriction was abolished for $2 \mathrm{~h}$ by pretreatment with a s.c. dose of $20 \mathrm{nmol} \mathrm{kg}^{-1}$ Hoe 140 administered $30 \mathrm{~min}$ before BK. Four hours after pretreatment, the inhibition in terms of $\mathbf{R}_{\mathrm{L}}$-increase was still $50 \%$ indicating a long biological half life of at least $4 \mathrm{~h}$ for this dose and route of administration.

Seven experiments were performed to determine whether large doses of Hoe 140 showed BK-agonist activity. In animals pretreated with propranolol, a dose of $1 \mu \mathrm{mol} \mathrm{kg}^{-1}$, i.v. increased $R_{L}$ by $16 \%$ from baseline, while $C_{D y n}$ was decreased by $14 \%$. When propranolol was omitted $(n=3)$ only slight transitory changes in $R_{\mathrm{L}}(+6 \%)$ and $\mathrm{C}_{\mathrm{Dyn}}(-5 \%)$ were observed.

\section{Carrageenin paw oedema in rats}

In the carrageenin-induced inflammation of the paws in rats, intravenous treatment $\left(0.01-1 \mathrm{mg} \mathrm{kg}^{-1}\right)$ inhibited the inflammatory response, the duration of action being longer when the dose was increased (Table 1).

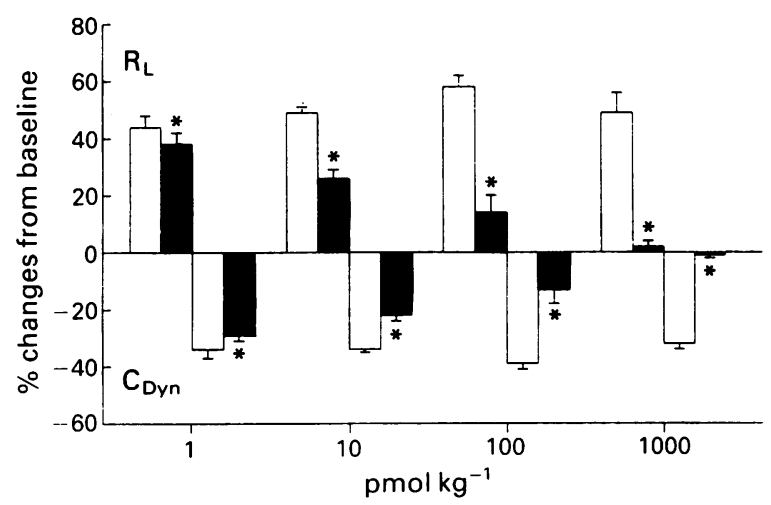

Figure 2 Dose-dependent inhibition of bradykinin (BK)-induced bronchoconstriction in anaesthetized guinea-pigs. Each column represents the mean of 3 to 6 animals before (open columns) and after (solid columns) i.v. administration of Hoe 140 (vertical bars show s.e.mean); ${ }^{*} P<0.05$.

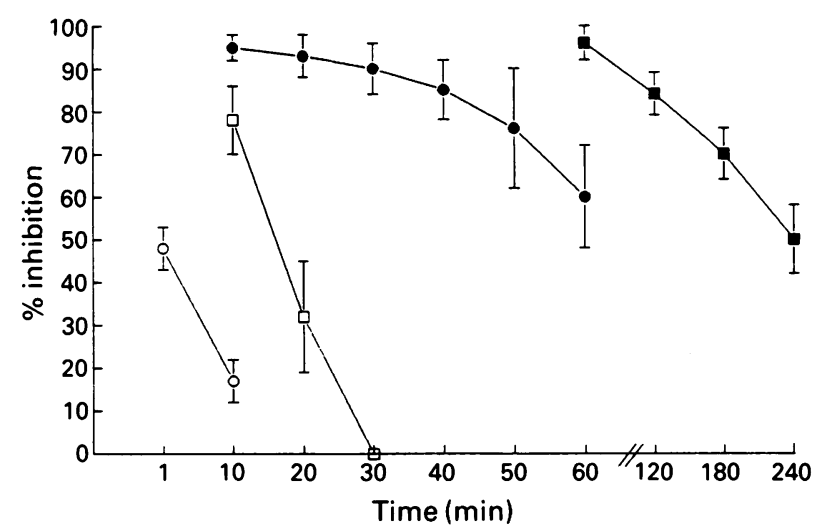

Figure 3 Duration of inhibition of bradykinin (BK)-induced increases in pulmonary resistance $\left(R_{L}\right)$ in anaesthesized guinea-pigs following different doses of Hoe $140\left(O, 0.01 \mathrm{nmol} \mathrm{kg}^{-1}\right.$, i.v., $\square$, $0.1 \mathrm{nmol} \mathrm{kg}^{-1}$, i.v.; $\odot, 1 \mathrm{nmol} \mathrm{kg}^{-1}$ i.v. and $\square, 20 \mathrm{nmol} \mathrm{kg}^{-1}$, s.c.). Each point represents the mean of 3 to 6 animals with s.e.mean shown by vertical bars.

\section{Effects of i.v. administration on blood pressure and heart} rate in conscious dog

In conscious dogs, administration of $\mathrm{D}-\mathrm{Arg}-\left[\mathrm{Hyp}^{2}, \mathrm{Thi}^{5,8}\right.$, D-Phe ${ }^{7}$ BK $(n=4)$ and Hoe $140(n=5)$ in doses of 0.01 and $0.1 \mathrm{mg} \mathrm{kg}^{-1}$ did not affect systolic, diastolic and mean arterial blood pressure (MAP) or heart rate during a $15 \mathrm{~min}$ observation period. At the highest dose of $1 \mathrm{mg} \mathrm{kg}^{-1}$ however, Hoe 140 decreased blood pressure drastically in two dogs out of two, for 5 to $10 \mathrm{~min}$ with concomitant symptoms like pain reaction, restlessness and hypersalivation. D-Arg-[Hyp ${ }^{2}$, $\mathrm{Thi}^{5,8}$, D-Phe ${ }^{7}$ BK $\left(1 \mathrm{mg} \mathrm{kg}^{-1}\right)$ induced restlessness, hypersalivation, panting and swelling of the mucous membranes in one dog out of four.

\section{Discussion}

Our results demonstrate that Hoe 140 is a highly potent BKantagonist in vivo with a long duration of action. In rats, $20 \mathrm{nmol} \mathrm{kg}^{-1}$ s.c. Hoe 140 showed a half life of protection against BK-induced hypotensive responses of more than $5 \mathrm{~h}$ whereas the effect of $200 \mathrm{nmol} \mathrm{kg}^{-1} \mathrm{D}-\mathrm{Arg}-\left[\mathrm{Hyp}^{2}\right.$, Thi ${ }^{5,8}$, D-Phe $\left.{ }^{7}\right]$ BK was not significant at any time. The higher potency and longer duration of action of Hoe 140 compared to D-Arg-[Hyp ${ }^{2}$, Thi ${ }^{5,8}$, D-Phe $\left.{ }^{7}\right]$ BK can be explained by a higher receptor affinity and in vitro stability (Hock et al., 1991). Hoe 140 is not a substrate for kininase II and is only slowly degraded in human plasma.

In anaesthetized guinea-pigs, Hoe 140 exerted strong protective effects against BK-induced bronchoconstriction. The magnitude and duration of the antagonism were dosedependent. Even low i.v. doses of 1 to $100 \mathrm{pmol} \mathrm{kg}^{-1}$ of Hoe

Table 1 Effects of Hoe 140 on carrageenin-induced paw oedema in rats

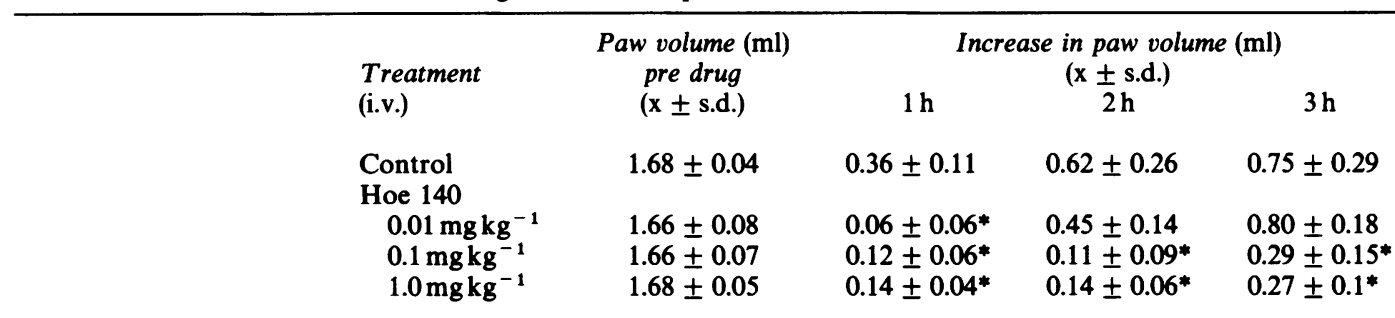

${ }^{*} P<0.05$ vs. control (Student's $t$ test) 
140 afforded short but considerable protection. At a s.c. dose of $20 \mathrm{nmol} \mathrm{kg}^{-1}$, the half life of the effect was estimated to be at least $4 \mathrm{~h}$. These results are consistent with the results and conclusions obtained in blood pressure experiments in rats concerning the potency and duration of action of Hoe 140. Only weak agonist activity assessed as an increase in pulmonary resistance $(+6 \%)$ was observed at the very high dose of $1 \mu \mathrm{mol} \mathrm{kg}^{-1}$ of Hoe 140 in the absence of propranolol. Propranolol enhanced this effect to a $16 \%$ increase in pulmonary resistance over baseline values. Selectivity against BK was demonstrated by the inability of Hoe 140 to inhibit bronchoconstriction induced by acetylcholine, histamine and 5hydroxytryptamine in a previous study using the method of Konzett and Rössler.

It has been proposed that BK has an important role in the events leading to allergic asthma and rhinitis (Proud \& Kaplan, 1988). It elicits contraction of tracheal smooth muscle in the guinea-pig in vitro as well in vivo. However, tachyphylaxis occurs in vivo in the absence of propranolol, probably due to the release of bronchodilator catecholamines from the adrenal glands by BK (Feldberg \& Lewis, 1967). Propranolol potentiates the effect of BK in the guinea-pig (Lau et al., 1989). The assumption of an involvement of BK in human asthma was based on the observation that BK induces bronchoconstriction in asthmatics but not in healthy subjects (Fuller et al., 1987) and further supported by the demonstration of increased BK levels in the bronchoalveolar lavage fluid of asthmatic patients (Christiansen et al., 1987). BK increases neuronal reflex activity (Kaufman et al., 1980) which causes the immediate bronchoconstrictor effect and neurophysiologically corresponds to hyperalgesia. Moreover, it exerts exudative and proinflammatory activity. These actions together could lead to the development of bronchial hyperresponsiveness and chronic inflammation of the airways. The

\section{References}

BARNES, P.J., CHUNG, F. \& PAGE, C.P. (1988). Inflammatory mediators and asthma. Pharmacol. Rev., 40, 49-83.

CHAPMAN, R.W., DANKO, G. \& SIEGEL, I.M. (1985). Effect of propranolol on pulmonary function and bronchoconstrictor responsiveness in guinea pigs and rats. Pharmacol. Res. Commun., 17, 149-163.

CHRISTIANSEN, S.C., PROUD, D. \& COCHRANE, C.G. (1987). Detection of tissue kallikrein in the bronchoalveolar lavage fluid of asthmatic subjects. J. Clin. Invest., 79, 188-197.

COSTELlO, A.H. \& HARGREAVES, K.M. (1989). Suppression of carrageenin-induced hyperalgesia, hyperthermia and edema by a bradykinin antagonist. Eur. J. Pharmacol., 171, 259-263.

FELDBERG, W. \& LEWIS, G.P. (1967). The action of peptides on the adrenal medulla: Release of adrenaline by bradykinin and angiotensin. J. Physiol., 171, 98-108.

FULLER, R.W., DIXON, C.M., CUSS, F.M.C. \& BARNES, P.J. (1987). Bradykinin-induced bronchoconstriction in humans. Am. Rev. Respir. Dis., 135, 176-180.

GRIESBACHER, T., LEMBECK, F. \& SARIA, A. (1989). Effects of the bradykinin antagonist B 4310 on smooth muscles and blood pressure in the rat, and its enzymatic degradation. Br. J. Pharmacol., 96, 531-538.

HARGREAVES, K.M., TROULLOS, E.S., DIONNE, R.A., SCHMIDT, E.A., SCHAFER, S.C. \& JORIS, J.L. (1988). Bradykinin is increased during acute and chronic inflammation: Therapeutic implications. Clin. Pharmacol. Ther., 44, 613-621.

HOCK, F.J., WIRTH, K., ALBUS, U., LINZ, W., GERHARDS, H.J. WIEMER, G., HENKE, ST., BREIPOHL, G., KÖNIG, W., KNOLLE, J. role of inflammatory mediators in asthma is extensively discussed by Barnes et al. (1988).

Based on the inflammatory actions of BK, receptor antagonists can be expected to reduce airway inflammation and subsequent destruction of lung tissue. Due to its high potency and long duration of action Hoe 140, given in adequate doses, can be expected to neutralize completely endogenous BK. This makes it important to answer the question as to whether antagonism of excess BK improves clinical asthma.

Hoe 140 markedly reduced carrageenin-induced rat paw oedema. This confirms the results obtained with another BKantagonist (Costello \& Hargreaves, 1989). Carrageenininduced inflammation has been shown to be highly predictive of anti-inflammatory drug activity in human inflammatory disease. BK is an important mediator in this rat model of inflammation. This was already anticipated by the finding that BK plasma levels rose after carrageenin-induced inflammation in rats (Hargreaves et al., 1988). The assumption of an involvement of BK in inflammation in human disease was strengthened by the observation that BK levels increased in plasma of patients with rheumatoid arthritis and after oral surgery (Hargreaves et al., 1988). Moreover, kallikrein levels are increased in joints of patients with rheumatoid arthritis (Selwyn et al., 1989).

Possible adverse affects of Hoe 140 were tested in dogs by i.v. injection and compared with D-Arg- $\left[\mathrm{Hyp}^{2}, \mathrm{Thi}^{5,8}\right.$ D-Phe ${ }^{7}$ BK. Doses of 0.01 and $0.1 \mathrm{mg} \mathrm{kg}^{-1}$ of both compounds were well tolerated. The symptoms observed with both antagonists at the very high dose of $1 \mathrm{mg} \mathrm{kg}^{-1}$ might be due to their residual BK-agonist activity (Hock et al., 1991).

In summary, our results show that Hoe 140 is a highly potent BK-antagonist with a long duration of action and a good efficacy/tolerability relationship for application in BKmediated diseases.
\& SCHÖLKENS, B.A. (1991). Hoe 140 a new potent and long acting bradykinin-antagonist: in vitro studies. Br. J. Pharmacol., 102, 769-773

KAUFMAN, M.P., COLERIDGE, H.M., COLERIDGE, J.C.G. \& BAKER, D.G. (1980). Bradykinin stimulates afferent vagal C-fibres in intrapulmonary airways of dogs. J. Appl. Physiol., 48, 511-517.

LAU, W.A.K., RECHTMAN, M.P., BOURA, A.L.A. \& KING, R.G. (1989). Synergistic potentiation by captopril and propranolol of bradykinin-induced bronchoconstriction in the guinea pig. Clin. Exp. Pharmacol. Physiol., 16, 849-857.

PROUD, D. \& KAPLAN, A. (1988). Kinin formation: mechanisms and role in inflammatory disorders. Ann. Rev. Immunol., 6, 49-83.

SACHS, L. (1984). Angewandte Statistik. p. 552. Berlin: Springer Verlag. SELWYN, B.M., FIGOUEROU, C.D., FINK, E., SWAN, A., DIEPPE, P.A. \& BHOOLA, K.D. (1989). A tissue kallikrein in the synovial fluid of patients with rheumatoid arthritis. Ann. Rheum. Dis., 48, 128-133.

VAVREK, R.J. \& STEWART, J.M. (1985). Development and modification of competitive antagonists of bradykinin. In Peptides, Structure and Function. Proc. 9th Amer. Peptide Symp. ed. Deber, C.M., Hruby, V.L. \& Kopple, K.D. pp. 655-658. Rockford IL: Pierce Chem. Comp.

WINTER, Ch.A., RISLEY, E.A. \& NUSS, G.W. (1962). Carrageenininduced edema in hind paw of the rat as an assay for antiinflammatory drugs. Proc. Soc. Exp. Biol., 111, 544-547.

(Received July 25, 1990

Revised October 22, 1990 Accepted November 19, 1990 